\title{
La unidad como componente de la Independencia: precursores de la integración latinoamericana en Santiago de Chile (1810-1813)
}

\section{The unity as a component of Independence: antecedents of Latin American integration in Santiago de Chile (1810-1813)}

\author{
Germán A. de la Reza ${ }^{2}$ \\ Universidad Autónoma Metropolitana (México)
}

Recibido: 28-02-15

Aprobado: 04-04-15

\section{Resumen}

En el presente artículo analizamos los primeros escritos independentistas difundidos en Santiago de Chile entre 1810 y 1813 desde la perspectiva de su aporte a la creación de las bases ideológicas que facilitarán la participación del país en posteriores iniciativas confederales hispanoamericanas. Las conclusiones de nuestra investigación refrendan la importancia de la idea del congreso general durante el periodo de la Patria Vieja y matizan la hipótesis sobre el monopolio del proyecto protonacional defendida por la historiografía mayoritaria.

Palabras-clave: Independencia de Chile, Congreso de Panamá (1826), Proyectos de unión hispanoamericana.

\footnotetext{
${ }^{1}$ El presente artículo forma parte del proyecto de investigación sobre Integración regional orígenes históricos. Se agradece al arbitraje anónimo sus comentarios y sus oportunas sugerencias.

2 (germandelareza@hotmail.com) Profesor investigador de la Universidad Autónoma Metropolitana - Unidad Xochimilco, miembro regular de la Academia Mexicana de Ciencias y del Sistema Nacional de Investigadores, nivel III. Sus investigaciones versan sobre distintos aspectos de la integración en América Latina. Entre sus trabajos sobre la historia del regionalismo, destacan: La invención de la paz. De la República cristiana del duque de Sully a la Sociedad de naciones de Simón Bolívar (2009); Documentos sobre el Congreso anfictiónico de Panamá (2010), y El ciclo confederativo. Historia de la integración latinoamericana en el siglo XIX (2012). En 2005-2006 ocupó la Cátedra Simón Bolívar de la Universidad de París.
} 


\begin{abstract}
In this article we analyze the first independentists writings disseminated in Santiago de Chile between 1810 and 1813 from the perspective of their contribution to the creation of the ideological foundations that will facilitate the country's participation in posterior Latin American confederal initiatives from 1821 to 1826 . The findings endorse the importance of the idea of the general congress during the Patria Vieja period, and challenge the assumption about the monopoly of proto national project championed by mainstream historiography.
\end{abstract}

Key-words: Independence of Chile, Congress of Panamá (1826), Projects of Hispanic American union.

A la memoria de Gustavo E. Emmerich Issac

\title{
Introducción
}

Los historiadores han estado más interesados en explicar los vínculos de los primeros escritos independentistas y la fundación de las nuevas repúblicas, que con las iniciativas transversales de unión hispanoamericana defendidas en casi todos ellos. Para avanzar en el esclarecimiento de este aspecto, en el presente artículo se analizan tres manifiestos difundidos en Santiago de Chile entre 1810 y 1813: el Catecismo político cristiano, la Declaración del pueblo de Chile y el Catecismo de los patriotas. Su contenido y otros documentos conexos se consideran desde la perspectiva de su aporte a la creación de las bases ideológicas que facilitarán la participación de Chile en las iniciativas confederales hispanoamericanas de 1821 a 1826 . El trabajo ha sido estructurado en cinco secciones: en la primera se revisan las determinantes generales de la Patria Vieja; en las tres siguientes, los escritos independentistas, y en la última su conexión con los ensayos de integración hispanoamericana en la década de 1820. Las conclusiones refrendan la relativa importancia de la idea del congreso general más allá del periodo juntista y en ese camino alumbran un aspecto eludido por la historiografía mayoritaria, cuyas narraciones de la Independencia sugieren que el proyecto nacionalista constituye la única opción postcolonial. En el plano metodológico, finalmente, asientan la necesidad de ampliar la temática y los actores del proceso de Emancipación de la antigua Capitanía General ${ }^{3}$.

${ }^{3}$ La tradición historiográfica propone cuatro periodos: Patria Vieja (1810-1814), Reconquista española (1814-1817), Patria Nueva (1817-1823) y Fin de la Guerra de Independencia (1823-1826). Sobre la necesidad de revalorizar actores y temas de la Independencia eludidos por la historiografía 


\section{Años de creación}

El contexto histórico que rodea la propagación de los primeros manifiestos independentistas comprende, entre otros hitos, la instalación de la Junta gobernativa de Chile a mediados de 1810; la firma de un tratado confederal con las Provincias Unidas del Río de la Plata en marzo de 1811; la instalación del primer Congreso en julio de ese año; la redacción y aprobación del Reglamento Constitucional Provisorio de 1812; la publicación del olvidado Decreto de sustitución de la bandera española por el lábaro "tricolor" a mediados de $1813^{4}$, y en final, el desastre de Rancagua en 1814.

Esos años, esencialmente de creación, como los califica Simon Collier ${ }^{5}$, permiten la transformación de la Capitanía General en un incipiente Estado, mutación que se acompaña de procesos de cambio en prácticamente todos los ámbitos. La elaboración "completa" de nuevas ideas políticas", uno de los aspectos sobresalientes del periodo, empieza a fraguarse a finales del siglo XVIII y principios del XIX al instar de la Revolución Francesa, la Revolución de Independencia de Estados Unidos y la influencia intelectual de la Ilustración. La biblioteca de José Antonio de Rojas en Santiago, la más grande y quizá la más ilustrativa de ese trasvase cultural, incluye en su catálogo las obras de ClaudeAdrien Helvecio, el Barón de Montesquieu, el Conde de Buffon, William Robertson, François Fénelon, Samuel Pufendorf, Benito J. Feijoo, el Barón D'Holbach, Jean Le Rond D'Alambert, Étienne B. de Condillac, Jean-Jacques Rousseau, Voltaire, Étienne G. Morelly, Guillaume T. Rayna y los 56 tomos de la Enciclopedia ${ }^{7}$. Una orientación similar, aunque de menores proporciones, ofrece la biblioteca de Manuel de Salas, además de la que probablemente trajo Antonio Berney de Francia y la adquirida por Bernardo O'Higgins en Londres bajo el influjo de la célebre colección de Francisco Miranda ${ }^{8}$.

Estimulados por estos ideales, los patriotas llevan a primer plano la necesidad de la educación popular. Para ello se valen de distintos medios y proyectos, incluso los periódicos oficiales, Aurora de Chile, El Monitor Araucano y El

tradicional, véase, entre otros: Eduardo Cavieres, "Lo deseado y lo ejecutado: ideas y acciones, temas y problemas sobre la Independencia nacional, las representaciones y la construcción de Estado", Espacio Regional, vol. 2, n 7, Osorno, 2010, págs. 25-37.

4 "Decreto del Gobierno sustituyendo la bandera tricolor en lugar de la Española", El Monitor Araucano, $\mathrm{n}^{\circ} 30$, Santiago, martes 15 de junio de 1813, pág. 124.

5 Simon Collier, Ideas y política de la independencia chilena, 1808-1833, Fondo de Cultura Económica, Santiago, 2012, págs. 113-114.

${ }^{6}$ Ídem.

7 Cristián Gazmuri, "Libros e ideas francesas en la gestación de la Independencia de Chile", Caravelle, $\mathrm{n}^{\circ}$ 54, Toulouse, 1990, págs. 188-190.

${ }^{8}$ No existe evidencia de tal influjo bibliográfico, aunque O’Higgins se reclama heredero espiritual de Miranda. Archivo Nacional, Archivo del don Bernardo O'Higgins, t. I, Editorial Nascimento, Santiago, 1946, págs. 26-29.

Araucaria. Revista Iberoamericana de Filosofía, Política y Humanidades, año 17, $\mathrm{n}^{\circ} 34$. Segundo semestre de 2015. Pp. 27-46. ISSN 1575-6823 e-ISSN 2340-2199 doi: 10.12795/araucaria.2015.i34.02 
Semanario Republicano ${ }^{9}$. Otro medio es la Biblioteca Nacional, creada en 1813 y cuyos directores son dos principales actores de la Independencia: Manuel de Salas y fray Camilo Henríquez ${ }^{10}$. Los proyectos educativos propiamente dichos prevén la utilización de los monasterios para la instrucción de las niñas y la fundación del Instituto Nacional en $1813^{11}$. El Instituto organiza cursos "sin pupilaje", ofrecidos a los adultos que desean ampliar sus conocimientos, y con pupilaje para los alumnos de todo el Estado. De forma a garantizar el acceso a la educación de las provincias y de los menos favorecidos, su reglamento estipula que las becas se adjudiquen en proporción al número de pobladores de cada localidad y se tenga en consideración la "disposición ventajosa del alumno" y su posible carencia de recursos económicos ${ }^{12}$.

La Junta también busca proteger a la nueva producción intelectual ${ }^{13}$. El Decreto del Gobierno sobre la Libertad de la prensa del 23 de junio de 1813, declara en su art. $1^{\circ}$ la "entera y absoluta libertad de imprenta" quedando "abolidas las revisiones, aprobaciones y cuantos requisitos se opongan a la libre publicación de los escritos". La supervisión de su práctica se deja en manos del Senado y éste comisiona a uno de sus miembros para que, sin su "audiencia", no pueda condenarse a ningún autor. Como complemento o equilibrio de esa instancia se crea una junta compuesta de siete personalidades con el encargo de recibir las reclamaciones por abuso de libertad ${ }^{14}$. Un mes más tarde, el Gobierno nombra a Juan Egaña en el cargo de comisionado ${ }^{15}$.

En el plano social, la Junta busca sobre todo hacer efectivas las proclamas de "fraternidad, igualdad y prosperidad". A principios de 1811, el Congreso decreta la igualdad de los indígenas con los demás ciudadanos del país y luego publica la ley de Libertad de Vientre y la prohibición de la importación de esclavos. En 1813, finalmente, aparece el Reglamento a favor de los ciudadanos indios cuyo objetivo, desglosado en quince artículos, establece la eliminación de los "campos" (aldeas) donde la población indígena vive en "extrema miseria,

\footnotetext{
${ }^{9}$ Así, el primer número de la Aurora publica el 3 de febrero de 1812 un largo artículo dedicado a las "Nociones fundamentales sobre los derechos de los pueblos".

10 Raúl Silva Castro, Los primeros años de la Biblioteca Nacional (1813-1824), Imprenta Universitaria, Santiago, 1951.

11 Miguel Luis Amunátegui, Los primeros años del Instituto Nacional, 1813-1835, Imprenta Cervantes, Santiago, 1889, pág. 70; Andrés Baeza Ruz, "Elightenment, education, and the republican Project: Chile’s Instituto Nacional (1810-1830)", Paedagogica Historica, vol. 46, n 4, 2010, págs. 479-493.

12 “Aviso a los pueblos", El Monitor Araucano n 39, Santiago, 6 de julio de 1813, págs. 137-140.

13 Actitud no siempre consistente. Un decreto del 2 de agosto de 1813 que circula internamente y se da a conocer recién en 1889, nombra como revisor de la Aurora a Juan Egaña. El decreto es resistido por su director por considerarlo una censura. Miguel Luis Amunátegui, Camilo Henríquez, edición oficial, t. I, Imprenta Nacional, Santiago, 1889, págs. 72-73.

14 "Decreto del Gobierno con acuerdo del Senado sobre la Libertad de la prensa", El Monitor Araucano $\mathrm{n}^{\circ}$ 35, Santiago, 26 de junio de 1813, págs. 140-145. Firman el Decreto Francisco Antonio Pérez, José Miguel Infante, Agustín Eyzaguirre y Mariano Egaña, este último como Secretario.

15 "Senado consulto participado al gobierno, 15 de julio de 1813", El Monitor Araucano n ${ }^{\circ} 49$, Santiago, 29 de julio de 1813, págs. 181-182.
} 
inercia, incivilidad, falta de moral y educación". El Gobierno planea sustituirlos por "villas formales" que permitan a sus residentes "gozar de los mismos derechos sociales de ciudadanía que corresponde al resto de los chilenos". Para costear su construcción invoca el "valor de los mismos pueblos", lo que deja su normativa en letra muerta, aunque su intención de borrar "por todos modos la diferencia de [condiciones] en un pueblo de hermanos", no es ajena a la sensibilidad de la época ${ }^{16}$.

\section{Catecismo político cristiano}

La múltiple efervescencia de la Patria Vieja sirve de marco de difusión a los primeros manifiestos independentistas. La pieza inaugural, el Catecismo político cristiano dispuesto para la instrucción de la Juventud de los Pueblos libres de la América Meridional, circula en manuscrito uno o dos meses antes de la convocatoria al cabildo abierto del 18 de septiembre de 1810. Su autor se esconde bajo el pseudónimo de "José Amor de la Patria", abriendo con ello una larga y sinuosa controversia sobre su identidad: durante varias décadas la mayoría de los historiadores atribuye su autoría al mendocino Juan Martínez de Rozas (1759-1813) ${ }^{17}$, otros al guatemalteco Antonio José de Irisarri (17861868) e incluso a O’Higgins (1778-1842). En 1943, el entonces director del Archivo Histórico, Ricardo Donoso, da término a una acuciosa investigación en la cual asienta que el autor del documento es uno de los líderes de los “doctores” de Chuquisaca, Jaime Zudáñez de la Torre (1772-1832) ${ }^{18}$.

Aunque a veces se esquive, la demostración de Donoso es sólida ${ }^{19}$. En efecto, el Catecismo politico cristiano alude en dos ocasiones a las sublevaciones

16 El Decreto precisa que cada familia dispondrá de dos departamentos "a lo menos" y "una propiedad rural, ya sea unida a su casa, si es posible, y de no en las inmediaciones de la villa"; asimismo, cada pueblo contará con una iglesia, una casa consistorial, una cárcel y una escuela. "Reglamento a favor de los Ciudadanos Indios", El Monitor Araucano n ${ }^{\circ} 37$, Santiago, $1^{\circ}$ de julio de 1813, págs. 130-133.

17 Martínez de Rozas realiza sus estudios en Córdova del Tucumán y Santiago. Más tarde ocupa una cátedra en el Real Convictorio Carolino y funge de asesor de la Intendencia de Concepción, luego es intendente interino y secretario del gobernador. Recorre la frontera pero radica la mayor parte del tiempo en Concepción, lugar donde lo encuentra la primera Junta, a la cual se integra el 1 de noviembre de 1810. En ese momento cuenta con 51 años. Martínez de Rozas nunca reivindica la autoría del Catecismo político cristiano aunque ayuda a su difusión. Sobre su actividad en la frontera, véase: Fernando Campos Harriet, "Don Juan Martínez de Rozas, jurista de los finales del periodo indiano", Actas y Estudios del VII Congreso del Instituto Internacional de Historia del Derecho Indiano, Buenos Aires, 1-6 de agosto, 1983, págs. 195-210.

18 Ricardo Donoso, "El Catecismo Político-Cristiano", Revista Chilena de Historia y Geografia, $\mathrm{n}^{\circ} 102,1943$, págs. 12-119.

${ }^{19}$ Collier (Ideas y política de la independencia chilena, pág. 91) y Walter Hanish Espíndola (El Catecismo político cristiano. Las ideas y la época: 1810, Editorial Andrés Bello, Santiago, 1970, pág. 16), entre otros, conocen la obra de Donoso aunque el primero prefiere pasar en silencio sus conclusiones y el segundo concentra sus energías en demostrar la "chilenidad" del Catecismo. 
de La Paz y Quito, así como a la expedición punitiva de Manuel Goyeneche en el Alto Perú (entonces un desconocido en Chile); nunca a hechos o topónimos de Chile, Mendoza o Centroamérica. Sus premisas tomistas y suarezianas son comunes en los debatesde la Universidad San Francisco Xavier de Charcas. En adición, la urgencia y la claridad de miras de su llamado a instalar la Junta y a cooperar con otros centros de la América española son coherentes con los ideales y la trayectoria del altoperuano. Él y su hermano Manuel habían participado en el levantamiento de Chuquisaca del 25 de mayo de 1809. Luego de ser hechos prisioneros, Manuel fallece en detención domiciliaria y él es remitido al penal del Callao en Lima. A su liberación parte a Santiago, donde continúa la lucha por la Independencia de América ${ }^{20}$. El empleo del pseudónimo en su caso se explicaría por la protección que requiere quien ha decidido perseverar en las actividades que habían ocasionado su encierro.

Una vez integrado a la élite santiaguina, Zudáñez participa junto a fray Henríquez, Salas, Irisarri, Francisco de Lastra, Hipólito Villegas y Francisco Pérez, en la redacción del Reglamento constitucional provisorio de 1812 , la primera constitución de Chile ${ }^{21}$. En julio de 1813 es nombrado miembro suplente de la Junta de supervisión del Reglamento de libertad de imprenta, teniendo entre sus compañeros a Martínez de Rozas y a Irisarri ${ }^{22}$. Ese año acumula dos cargos más: la Secretaría interina de Relaciones Exteriores en cuya función suscribe el Manifiesto a las naciones de América y Europa a favor de la libertad de comercio- ${ }^{23}$, y la judicatura del Supremo poder judiciario ${ }^{24}$. En octubre dimite de ambas responsabilidades para mudarse a Buenos Aires, ${ }^{25}$ aunque antes asesora a O’Higgins en las negociaciones del Tratado de Lircay de $1814^{26}$.

20 José Luis Roca, Ni con Lima ni con Buenos Aires. La formación de un Estado nacional en Charcas, Plural Editores, segunda edición, La Paz, 2011, págs. 397-408.

${ }^{21}$ El Reglamento Constitucional Provisorio del Pueblo de Chile subscripto por el de la Capital, presentado para su subscripción a las provincias (Imprenta de Gobierno por S. B. Johnston y S. Garrison, 26 de octubre de 1812), fue elaborado a partir del borrador del ministro plenipotenciario estadounidense, Joel R. Poinsett, documento publicado por Cristian Guerrero Lira en "El proyecto constitucional de J. R. P. para Chile, 1812, Cuadernos de Historia, vol. 37, Santiago, 2012, págs. 225 240. Sobre los aspectos colaterales, véase Cristóbal García-Huidobro, "El Reglamento Constitucional Provisorio de 1812: Reflexiones para un Bicentenario", Revista Chilena de Derecho, vol. 39, n 1 , Santiago, 2012, págs. 235-243.

22 "Vocales de la Junta, $1^{\circ}$ de julio de 1813", El Monitor Araucano n ${ }^{\circ} 40$, Santiago, 8 de julio de 1813, pág. 142 .

${ }^{23}$ Francisco A. López (Presidente), José M. Infante, Agustín Eyzaguirre y Jaime Zudáñez (Secretario interino de Relaciones Exteriores), Manifiesto del Gobierno de Chile a las naciones de América y Europa, Imprenta de Gobierno, P. D. J. C. Gallardo, Santiago, 1813.

24 "Anuncio del Gobierno, 19 de agosto de 1813", El Monitor Araucano n 64, Santiago, 4 de septiembre de 1813, pág. 211.

25 "Artículo oficial", El Monitor Araucano n 82, Santiago, 19 de octubre de 1813, págs. 139-140.

${ }^{26}$ Claudio Gay, Historia de la Independencia Chilena, t. II, Impr. de E. Thunot, París, 1856, pág. 76. Antes de su partida de Santiago, aparecen en El Monitor Araucano cartas "fidedignas" de patriotas alto peruanos remitidas a un interlocutor en el que confía, probablemente Zudáñez. A su llegada a Buenos Aires, "el permanente expatriado" deviene asesor del cabildo y representa a Charcas en el congreso de 
Los argumentos del Catecismo político cristiano se exponen en forma de diálogo. En una de sus sentencias se define a las juntas españolas (organizadas en la Península durante la ocupación francesa) como instancias legítimas de gobierno local pues se basan en el principio de representatividad. No por esto, agrega el autor, pueden mandar sobre las secciones de América, ya que estas deben obediencia sólo al rey, entonces en cautiverio. Ese argumento, ya defendido por la escolástica de San Francisco Xavier en rechazo a las pretensiones de dominación de la Junta Suprema de España e Indias instalada en Sevilla, aunado a la deficiente representación americana en las negociaciones con la Península y a los atropellos cometidos por los realistas en La Paz y Quito, llevan al autor a proponer la reunión de un cabildo abierto para acordar y decidir sobre el destino de la Capitanía General. Su proyecto comporta tres pilares: organizar un gobierno provisional; convocar a los delegados "para que hagan la constitución", y crear un congreso americano. Los tres proveen de sentido constituyente, republicano y confederativo a una coyuntura por entonces se limita a reclamar mayor autonomía dentro del Imperio español:

Unámonos a nuestros hermanos con vínculos eternos, por la alianza del cañón y la fuerza de las bayonetas. Es necesario convocar un cabildo abierto, formado por vosotros mismos en caso necesario y allí hablaremos, acordaremos y decidiremos de nuestra suerte futura con la energía y dignidad de hombres libres: hagamos lo que han hecho en otras partes, formar desde luego una junta provisional que se encargue del mando superior y de convocar los diputados del reino para que hagan la constitución y su dicha: el congreso general, la representación nacional de todas las provincias de la América meridional, residirá donde acuerden todas ${ }^{27}$.

Si llegara a fracasar una de estas iniciativas -al autor le preocupa sobre todo la no instalación de la asamblea general-, la "división, la falta de acuerdo y de unión" resultantes desencadenarían algo "mil veces peor que la pérdida de la mitad de nuestros derechos"28. El Catecismo es claro respecto de la necesidad de considerar la unión como un componente y una condición de éxito de la

Tucumán de 1816. Más tarde en Uruguay se desempeña como asesor y auditor de guerra, y preside la comisión encargada de elaborar la constitución del país, aprobada el 19 de septiembre de 1829. Antes de su deceso en Montevideo preside el Tribunal de apelaciones uruguayo. Estanislao Just Lleó, Comienzo de la independencia en el Alto Perú: los sucesos de Chuquisaca, 1809, Editorial Judicial, Sucre, 1994; El Monitor Araucano, t. I, n 82, Santiago, 19 de octubre de 1813; Joseph M. Barnadas, Diccionario histórico de Bolivia, t. II, Grupo de Estudios Históricos, Sucre, 2002, pág. 1215.

27 José Amor de la Patria, "Catecismo político Cristiano dispuesto para la instrucción de la Juventud de los Pueblos libres de la América Meridional”, Colección de historiadores i de documentos relativos a la independencia de Chile, vol. XVIII, Imprenta Cervantes, Santiago, 1910, pág. 133.

${ }_{28}$ Ídem. Otra contribución del texto es su defensa del régimen republicano, "el único que conserva la dignidad y majestad del Pueblo: es el que más acerca, y el que menos aparta a los hombres de la primitiva igualdad en que los ha creado el Dios Omnipotente; es el menos expuesto a los horrores de despotismo, y de la arbitrariedad; es el más suave, el más moderado, el más libre, y es, por consiguiente, el mejor para hacer felices a los vivientes racionales". 
Emancipación. Sin embargo, los historiadores del periodo han glosado esta idea sin reparar en su significado para la cabal comprensión del texto y de su vínculo con las iniciativas confederales de la década de 1820 .

Sobre este asunto volveremos al final del artículo; baste advertir que los llamados a la organización de un "congreso general" son numerosos en la época. Figuran en los tratados bilaterales de unión, liga y confederación perpetua concluidos entre 1821 y 1826; en la invitación al Congreso anfictiónico de Panamá del 7 de diciembre de $1824^{29}$; en la convocatoria mexicana al congreso de unión hispanoamericana despachada en $1831^{30}$; en la invitación al Congreso americano de Lima de $1846^{31}$; en los preliminares del Tratado Continental o Tripartito de Santiago de $1856^{32}$, y en la nota circular para la organización del Segundo Congreso de Lima en $1864^{33}$. En cada caso las cancillerías conciben la instalación del congreso general como un medio para lograr la adecuada defensa de sus repúblicas. Hecho notable, siempre proponen el mismo esquema de unión, diferente de la federación o la confederación más estrecha en que permite mayor despliegue a las soberanías de los Estados. ${ }^{34}$

\section{Declaración de los derechos del pueblo de Chile}

El 26 de noviembre de 1810, la Junta gobernativa de Chile envía a su homóloga de Buenos Aires un documento en el cual expresa, entre otras ideas, su deseo de ver unida a Hispanoamérica, "base de nuestra seguridad exterior y aun interior" ${ }^{35}$. Para la realización de este proyecto, su autor, Juan Egaña Risco (1769-1836), recomienda la organización de un congreso de representantes de

29 Si el congreso general no se reúne, dice el texto, esta situación creará "retardos y perjuicios inmensos a tiempo que el movimiento del mundo lo acelera todo, pudiendo también acelerarlo en nuestro daño". Simón Bolívar y José Faustino Sánchez Carrión, Invitación a formar el Congreso de Panamá, 7 de diciembre de 1824, en Germán A. de la Reza, Documentos sobre el Congreso anfictiónico de Panamá, Fundación Ayacucho, Caracas, 2010, pág. 42.

${ }^{30}$ Instrucciones generales a los ministros Cañedo y Díez de Bonilla, México, 3 de junio de 1831, Francisco Cuevas Cancino, El pacto de familia. Historia de un episodio de la diplomacia mexicana en pro de la anfictionía, Secretaría de Relaciones Exteriores, México, t. I, 1962, pág. 131.

31 Nota circular de invitación, Lima, 9 de noviembre de 1846, Alberto Ulloa, Congresos americanos de Lima, t. I, Archivo Diplomático del Perú, Imprenta Torres Aguirre, Lima, 1938, págs. 179-180.

32 Tratado Continental, Santiago, 15 de septiembre de 1856, Ídem, pág. 613.

33 Nota circular de invitación al Congreso americano, Lima, 11 de enero de 1864, Ídem, págs. $337-342$

${ }^{34}$ Germán A. de la Reza, El ciclo confederativo. Historia de la integración latinoamericana en el siglo XIX, Universidad de San Marcos, Lima, 2012. La obra examina la correspondencia diplomática relativa a los tratados confederativos hispanoamericanos entre 1821 y 1865 , y observa la recurrencia del modelo anfictiónico gracias, en parte, al prestigio del que goza el Congreso de Panamá.

35 Junta gobernativa de Chile al Gobierno de Buenos Aires, 26 de noviembre de 1810, Manuel Antonio Tocornal y Grez, Memoria sobre el primer gobierno nacional, leida en la sesión pública de la Universidad de Chile el 7 de noviembre de 1847, Editorial El Progreso, Santiago, 1866. 
las provincias de Hispanoamérica ${ }^{36}$. El plan comparte miras con el Catecismo político cristiano, así como con el Dictamen de José Gregorio Argomedo (1767-1830), favorable a la reunión de los delegados americanos ${ }^{37}$, aunque en su caso se trata de una empresa ecuménica que se promoverá varias veces hasta el final de la Guerra de Independencia.

El nacimiento de Egaña en Lima, el origen peruano de su madre y el chileno de su padre han alentado una controversia sobre cuál de las dos nacionalidades debe considerarse como la predominante. Egaña no parece haber resentido las complicaciones de esta disyuntiva: tan tarde como 1827, la entrada de uno de sus libros lo presenta como "ornamento y lumbrera de la república de Chile, honor y gloria de la del Perú, en cuya capital vio la primera luz"38. Cumplidos los veinte años, Egaña se gradúa de la Universidad de San Marcos y parte a Santiago. En 1790, la Universidad de San Felipe le reconoce el título de abogado y le permite fungir como profesor de latín y retórica. Después de participar en la Junta gubernativa de 1810 asiste al Congreso constituyente de 1811 en calidad de diputado por Melipilla. Enseguida colabora en la redacción del Reglamento constitucional, preside el Senado, impulsa la creación del Instituto Nacional, forma parte de la Junta de 1813, escribe diversas obras en defensa del sistema republicano y de unión hispanoamericana, e incursiona en los géneros literario y filosófico ${ }^{39}$.

El Proyecto de Constitución de 1811 lleva como preámbulo su célebre Declaración de los derechos del pueblo de Chile, publicada finalmente en $1813^{40}$. Uno de sus preceptos asienta la necesidad de salvaguardar las nuevas soberanías, organizar y fortificar el movimiento independentista apelando a la

36 Diego Barros Arana et al., Colección de historiadores $i$ de documentos relativos a la independencia de Chile, vol. XIX, Imprenta Cervantes, Santiago, 1911, págs. 97-109.

37 Días antes de la instalación de la Junta de 1810, Argomedo, rector de San Felipe y asesor del Cabildo, difunde un Dictamen en el cual propone la reunión de un congreso de las provincias de América a la cual concurra un diputado "representante del reino de Chile", sea en España o en "aquel lugar de América que se designase como punto de reunión para tratar del gobierno de todas las Américas" (Art. 5). Argomedo, "Diario de los sucesos ocurridos en Santiago desde el 10 hasta el 22 de septiembre de 1810”, La Revista Nueva, Año I, t. II, Santiago, 1900, pág. 142.

38 Egaña, Memoria politica sobre si conviene en Chile la libertad de cultos. Reimpresa en Lima con una breve apología del art. 8 y 9 de la constitución política del Perú de 1823, Imprenta por La Libertad por J. M. Masias, Lima, 1827.

${ }^{39}$ Entre estas obras figura el sorprendente Tractatus de re Logica, Metaphisica et Morali (Tipografía Raimundo Rengifo, Santiago, 1827), escrito en latín para ser empleado como manual de lógica en el Instituto Nacional.

40 Egaña, Proyecto de una constitución para el Estado de Chile que por disposición del Alto Congreso escribió el senador D. D. Juan Egaña en el año 1811 y que hoy manda publicar el Supremo Gobierno, modificado según el dictamen que por orden del mismo Gobierno le precede El Proyecto de declaración de los derechos del pueblo de Chile, modificado según el dictamen que por orden del mismo Gobierno se pidió al autor, Imprenta del Gobierno por D. J. C. Gallardo, Santiago, 1813; Valentín Letelier, Sesiones de los Cuerpos Legislativos de la República de Chile. 1811 a 1845, t. I, Imprenta Cervantes, Santiago, 1887. Referencias a una primera versión figuran en Amunátegui, Los precursores de la Independencia de Chile, t. III, Imprenta, Litografía y Encuadernación Barcelona, Santiago, 1910, pág. 537.

Araucaria. Revista Iberoamericana de Filosofía, Política y Humanidades, año 17, n 34. Segundo semestre de 2015. Pp. 27-46. ISSN 1575-6823 e-ISSN 2340-2199 doi: 10.12795/araucaria.2015.i34.02 
unificación de Hispanoamérica. Agrega una incitación que anticipa el espíritu de futuras iniciativas:

El día en que América reunida en un congreso, sea de sus dos continentes, sea del continente del sur, hable al resto de la tierra, su voz se hará respetar y sus soluciones serán difícilmente contradichas ${ }^{41}$.

El Proyecto de una reunión general de las colonias españolas, escrito posterior de gran calidad intelectual, convoca a la organización del congreso esta vez "con la debida celeridad" ${ }^{42}$. Sugiere que la primera sesión la compongan los delegados sudamericanos "hasta que pueda ser llamada y tenga tiempo para concurrir la [sección] del Norte". En su visión, la integración de Buenos Aires, Chile y Perú representa el primer paso (o el segundo, si se consideran las propuestas hechas exclusivamente a Buenos Aires $)^{43}$ en la creación del "gran Estado de la América Meridional"44. La Dieta general se compondrá de tres consejeros por país (art. $3^{\circ}$ ); su sede será rotativa, pasando de una a otra capital de los países miembros (art. $5^{\circ}$ ) y sus funciones incluirán la sanción de los tratados de comercio recíprocos y con terceros países (art. $7^{\circ}$ ). Para evitar disensos entre los países miembros, propone que cada Estado dicte sus propias leyes sin intervención externa (art. $2^{\circ}$ ). Las restantes estipulaciones definen las facultades de la Dieta, la norma de operación de los consejeros y las aportaciones en efectivos de cada país para la protección de la confederación, entre otras.

Para el "principal pensador de la Independencia chilena"45, el peligro que asecha a Hispanoamérica no es la posibilidad de la reconquista española, sino otro más acuciante: su eventual atomización. Los "planes de Europa”, advierte, están dirigidos contra "nuestra flaqueza y división". El Viejo Continente pasa por grandes dificultades económicas acentuadas por el éxodo de trabajadores y hombres de cultura hacia Estados Unidos; ese proceso podría detenerse si la América antes española queda en incapacidad de formar su industria, creando las condiciones para el relanzamiento de la producción y el empleo en Europa.

${ }^{41}$ Ídem. Gustavo Cid Celis, Juan Egaña, constitucionalista y prócer americano, Imprenta El Esfuerzo, Santiago, 1941, págs. 18, 186 y ss.

${ }^{42}$ Egaña, "Proyecto de una reunión general de las colonias españolas para su defensa y seguridad en la prisión de Fernando VII", Silva Castro, Juan Egaña. Escritos inéditos y dispersos, Imprenta Universitaria, Santiago, 1949, págs. 43-52

43 De estos acercamientos es portavoz Francisco Antonio Pinto, enviado especial de la Junta. Poco después Egaña lo instruye que lleve a Londres la solicitud de reconocimiento diplomático y le comunica el proyecto de asamblea general. Egaña, "Instrucción remitida al Encargado de Negocios en la Corte de Londres y Enviado Extraordinario Don Francisco Antonio Pinto", Santiago, junio de 1813, Silva Castro, Escritos inéditos y dispersos, págs. 139-140.

${ }^{44}$ Egaña, "Dieta Soberana de Sud América, Silva Castro, Escritos inéditos y dispersos, págs. 52-58.

${ }^{45}$ Mario de Góngora, "El pensamiento de don Juan Egaña sobre la reforma eclesiástica", Estudios de historia de las ideas e historial social, Universidad Católica de Valparaíso, Santiago, 1980, pág. 183. 
Egaña no ignora que los impulsos separatistas más importantes vienen del interior, no del exterior. Tres factores coadyuvan en ese sentido: la falta de homogeneidad de los sistemas políticos propuestos por las juntas; "la tentación de los mandatarios de preservar el poder aún a costa de que sus hermanos hispanoamericanos sean dominados por potencias extranjeras"; y que los "pueblos más afectos a su independencia [otorguen] ventajas de comercio que los deje más esclavos que el Indostán”. Ese remarcable diagnóstico en una época en que Hispanoamérica todavía no ha roto los lazos de fidelidad hacia el rey, contempla "un remedio universal", "capaz de destruir todos los planes que la Europa haya formado en mil siglos":

la reunión de toda la América y el prestarse una defensa mutua para todos sus puntos organizando un plan general de las obligaciones y contribuciones que debe hacer cada gobierno en armas, hombre y dinero para el caso del menor ataque o seducción de la Europa. Ningún gobierno, tenga la opinión que tuviere, puede negarse a este servicio al rey y a la patria, y el que por una cruel ambición y malvada política busque especiosos pretextos para no concurrir, sería detestado de sus mismos pueblos como el monstruo devorador de la pacífica e inocente sangre de América. Para evitar aún esos pretextos, por ahora deberán reducirse los pactos a los únicos dos objetos de sostener mutuamente la integridad de las posesiones españolas de la América y su inviolabilidad por ningún ataque extranjero sin pasar al sistema de conservación doméstica e interior de cada gobierno, y cuando más el Congreso que se formase debe servir de conciliador y consultor para las opiniones particulares de los gobiernos, a fin de evitar guerras entre los gobiernos y los pueblos ${ }^{46}$.

El congreso encargado de definir el "régimen exterior de América" debería tener su sede en Guayaquil o en sus inmediaciones, y en caso que asista México, en "Panamá o alguna ciudad inmediata". Si bien este proyecto tiene varias versiones que buscan adaptarse "a las necesidades emergentes" ${ }^{47}$, en conjunto anticipan la suma de propósitos que enarbolará en su día el Congreso de Panamá: organizar la defensa y la diplomacia exterior de Hispanoamérica; hacer del congreso un conciliador en las diferencias de las distintas soberanías; no entrometerse en el ordenamiento político interno de cada país; y elegir como sede de la asamblea a una ciudad intermedia entre los extremos norte y sur del continente, concretamente el Istmo. Como veremos más adelante, Egaña promoverá este esquema hasta la década de 1820 , buscando su convergencia con el proyecto bolivariano. 46-47.

${ }^{46}$ Egaña, "Proyecto de una reunión general", Silva Castro, Escritos inéditos y dispersos, págs.

47 Silva Castro, “Juan Egaña, Precursor de la Integración Americana”, Estudios Internacionales, vol. 2, n 3, Instituto de Estudios Internacionales de la Universidad de Chile, Santiago, 1968, pág. 387. 


\title{
Catecismo de los patriotas
}

Los días 27 y 30 de noviembre de 1813, El Monitor Araucano publica en dos partes el Catecismo de los Patriotas escrito por su director, Camilo Henríquez (1769-1825), el socializador del ideario de las Luces durante el periodo de la Patria Vieja ${ }^{48}$. Henríquez realiza sus primeros estudios en el Convictorio Carolino de Santiago y parte a Lima en 1784 para concluir su formación eclesiástica y luego incorporarse a la orden de los Ministros Agonizantes de San Camilo de Lelis (de la Buena Muerte). Durante los veinticinco años que pasa fuera de Chile, frecuenta los círculos literarios y se familiariza con las obras de la Ilustración a tal punto que es detenido e interrogado por el Tribunal del Santo Oficio de Lima. Tras ese episodio, viaja a Quito en 1809 y de ahí regresa a Chile para unirse al movimiento independentista. Ya en Santiago se relaciona rápidamente con los juntistas, sobre todo con Salas e Irisarri.

El Catecismo de los Patriotas está redactado en el mismo estilo del Catecismo político cristiano, aunque descree del proyecto americanista y en su mayor parte se ocupa de definiciones cívicas: qué es un patriota, qué es lo que debe tener en su corazón, de qué depende la prosperidad pública, etc. En su concepto, "una de las señales más claras de la libertad pública" es la libertad de imprenta. Los beneficios de su ejercicio incluyen la posibilidad de denunciar los abusos, difundir las "buenas ideas", intimidar a las personas dañinas, dar a conocer propuestas de reglamentos y reformas, combatir los sistemas perjudiciales e impartir el conocimiento humano. A diferencia de los prelados de la época, que todavía defienden la lealtad al rey, Henríquez opta decididamente por el sistema republicano. Sostiene asombrosamente que el régimen monárquico fue aceptado por Dios "con disgusto" y que el peor de todos es el colonial. El colonialismo:

\begin{abstract}
está en contradicción con la libertad de los pueblos, y [...] enseña la experiencia que desde una inmensa distancia son mal gobernados, no se les administra bien la justicia, y sus productos y riquezas no se consumen en utilidad del propio país, sino en guerras y en el lujo y los vicios de la Corte.
\end{abstract}

En el tema de la asamblea general representa una suerte de antítesis del Catecismo político cristiano, de los escritos de Egaña o de Argomedo. A sus ojos es más útil un sistema de relaciones bilaterales, pues:

La América es mui vasta, i son mui diversos nuestros jenios, para que toda ella reciba leyes de un solo cuerpo legislativo. Cuando más pudiera formarse una reunión de plenipotenciarios para convenir en ciertos puntos indispensables; pero, como los de mayor interés i necesidad son una protección recíproca, i la

${ }^{48}$ Amunátegui, Camilo Henríquez, Imprenta Nacional, t. II, Santiago, 1889, págs. 53 y 65. 
unidad del fin e intentos, i todo esto puede establecerse i lograrse por medio de enviados de gobierno a gobierno, no parece necesaria tal asamblea. Ella, verdaderamente, se presenta a la fantasía con un aspecto mui augusto, pero no pasará de fantasía. El abad de San Pedro deseó cosas mui buenas, pero no se realizan los proyectos más útiles ${ }^{49}$.

La desconfianza que le inspira la idea del congreso general lo hace referirse a su posible ejecución "con una sonrisa un tanto burlona"50 y plaza su apertura en el año 2440. Observemos en sus razones un pronunciado carácter libresco. En efecto, cita al "abad de San Pedro", autor de un proyecto de confederación europea publicado en 1713 cuyo contenido se conoce en América a través de dos trabajos de Rousseau, un extracto y un juicio crítico $^{51}$; luego lo califica de utópico, como hace Rousseau en el segundo escrito, y lo ridiculiza como Voltaire en uno de sus relatos satíricos ${ }^{52}$. Henríquez con seguridad conoce a ambos autores: sus obras figuran en la biblioteca de Rojas y un ejemplar del Contrato social se encontró en el domicilio limeño de este prelado durante el proceso que le siguió la Inquisición ${ }^{53}$. La mención del año "2440" también tiene reminiscencias literarias: Louis-Sébastien Mercier publica en 1770 una novela intitulada L'Année 2440, en la cual describe la experiencia de un hombre que se despierta ese año en una suerte de Utopía, una ciudad en la que no existe la opresión, reinan las luces y la justicia ${ }^{54}$. Sin duda, Henríquez dialoga dentro de la tradición literaria europea; quizá eso lo lleve a subestimar la debilidad de la primera independencia chilena, la cual sucumbirá meses después en Rancagua.

¿Nunca modificó Henríquez su recelo hacia la unidad hispanoamericana? Existe una remota posibilidad. En 1813, El Monitor publica en varios números (64, 65, 66 y 67) un artículo brillantemente redactado: Reflexiones sobre la libertad Americana. No lleva firma y su argumento menciona a México, Caracas, Quito y Potosí, nunca a Chile. El único dato local es la referencia al periódico la Aurora junto a "periódicos de Buenos Aires", "diarios de las Cortes" y "papeles de Londres". Cabe precisar que Henríquez solía escribir en los periódicos que estaban a su cargo; la Aurora, el primero que dirigió, advierte en uno de sus números que los artículos sin "nombre o cifra de sus autores, son

\footnotetext{
${ }^{49}$ Anuncio, Aurora de Chile, n 28, t. I, 20 de agosto de 1812, Santiago, pág. 1.

50 Amunátegui, Camilo Henriquez, Imprenta Nacional, t. I, Santiago, 1889, pág. 90.

${ }^{51}$ El resumen se publica con el título de Extrait du Projet de paix perpétuelle de Monsieur l'abbé de Saint-Pierre en 1761 en la librería Bastide de París. La crítica -Jugement sur le projet de paix perpétuelle de l'abbé de Saint-Pierre- Rousseau no la publica en vida.

${ }_{52}$ Voltaire, De la paix perpétuelle par le docteur Goodhearth, M.M. Rey, Amsterdam, 1769.

53 Silva Castro, "Introducción”, Escritos politicos de Camilo Henriquez, Universidad de Chile, Santiago, 1960, págs. 60 .

${ }^{54}$ Louis-Sébastien Mercier, L'An deux mille quatre cent quarante, Rêve s'il en fut jamais, Londres, 1772 (falso pie de imprenta; probablemente se editó en Francia uno o dos años antes).
} 
obra del editor" "55. Como fuere, el hecho es que el artículo en cuestión contiene una breve y contundente defensa de la necesidad de unificar a Hispanoamérica:

\begin{abstract}
Habrían sido mayores y su esclavitud más cierta si cada cuatro pueblos hubiesen dado en el raro pensamiento de erigirse en soberanías y depender de si solas. Pero reunidos todos hubiesen formado en ambas Américas dos o más grandes masas, dos o más grandes cuerpos políticos, compuestos de cierto número de círculos o Estados que formasen o por sus representantes o de otro modo un gobierno único y central, seguramente nada habrían envidiado, ni el Cuerpo germánico, ni al Cuerpo Helvético, ni al Bátavo, ni a la República federal de Estados Unidos ${ }^{56}$.
\end{abstract}

El párrafo comparte con el proyecto de congreso general varias ideas: unión de los Estados apelando al régimen confederal (el autor agrega la posibilidad de la federación); defensa mancomunada frente a la agresión externa, y efecto disuasivo sobre sus eventuales enemigos. Llegado aquí es menester atenernos a dos principales evidencias: Henríquez nunca se desdice de su escepticismo, y ese sentimiento no es infrecuente en la época y terminará por imponerse en la década de 1820. Después de 1829, Andrés Bello alineará la diplomacia del país en función de una estrategia de contactos bilaterales que no cambiará sino en 1844, cuando el gobierno adhiera a la organización del Congreso de Lima de $1846^{57}$. Antes de ello, las razones del Ministerio de Relaciones Exteriores para rechazar las iniciativas de unión no son diferentes a las de Henríquez.

\title{
El proyecto de congreso general en los años 1820
}

En consonancia con la capitulación del ejército bonapartista en la Península, a partir de 1814 las fuerzas realistas recuperan posiciones en América y una a una, las juntas son disueltas y grupos de patriotas parten al exilio. Durante ese periodo se organizan en Buenos Aires diversas expediciones y los patriotas acumulan fuerzas para levantar el Ejército de los Andes comandado por José de San Martín. En 1817 y 1819, este Ejército, que incluye la División de O’Higgins, vence a los españoles en las batallas de Chacabuco y Maipú, y se hace con el control del país.

\footnotetext{
55 Anuncio, Aurora de Chile, $\mathrm{n}^{\circ} 29$, Santiago, 1812.

56 Anónimo, "Reflexiones sobre la libertad Americana", El Monitor Araucano, n 64, sábado 4 de septiembre de 1823, Santiago, págs. 242-243.

${ }^{57}$ En un artículo publicado ese año, Bello afirma que aún si no lograsen todos los objetivos del congreso, el hecho de poder estrechar las relaciones y avanzar en la regulación de las relaciones entre los países vecinos haría de su instalación una iniciativa provechosa. Andrés Bello, "Congreso americano", El Araucano, 1844, Obras Completas, Vol. X, Impreso por Pedro G. Ramírez, Santiago, 1886, págs. 493-507.
} 
Un año después, O’Higgins reactiva la solidaridad regional y propone llevar la Independencia al Perú. Escribe a Bolívar para "combinar" sus ejércitos, aunque la misiva nunca llega a destino ${ }^{58}$. Sin desistir, en junio de 1821, el Senado chileno instruye a su enviado especial a Bogotá para que impulse la creación de una confederación ${ }^{59}$; por su parte y casi al mismo tiempo, Bolívar envía dos ministros a Centro y Sudamérica con la misión de preparar el Congreso de Panamá ${ }^{60}$. Los tratados sureños se firman con el Perú el 6 de junio de $1822^{61}$ y con Chile el 21 de octubre de $1823^{62}$; los norteños con México el 3 de octubre de $1823^{63}$ y con la Federación de Centro América el 15 de marzo de $1825^{64}$. Estos cuatro tratados representan la piedra angular del Congreso de Panamá. Son prácticamente idénticos para permitir su posterior fusión, uniformiza objetivos y agenda, y establece el compromiso formal de que cada gobierno envíe al Istmo a dos ministros plenipotenciarios.

Con estos antecedentes, Chile era un casi seguro participante en el Congreso de Panamá. Sin embargo, el escepticismo y los temores de la clase política chilena a partir de la renuncia de O'Higgins al cargo de Director Supremo y su refugio en el Perú, terminan por hacer mella en su compromiso. El cambio de actitud lo ilustra la prensa santiaguina de 1825. En julio, La Abeja Chilena anuncia "con el mayor placer las gestiones que se están practicando para verificar la Asamblea Hispanoamericana" ${ }^{65}$. Semanas después, la Década

58 Barros Arana, Historia General de Chile, t. XII, Editorial Universitaria y Centro de Investigaciones Diego Barros Arana, segunda edición, Santiago, 2005, págs. 41-42.

59 Art. 7, "Instrucciones", Acta de la Sesión del 22 de junio de 1821, Sesiones de los Cuerpos Legislativos, t.. V, pág. 328. http://es. wikisource.org/wiki/Sesiones_de_los_Cuerpos_Lejislativos_ de_la_Rep\%C3\%BAblica_de_Chile_(1810-1845)

${ }_{60}$ Bolívar al Director Supremo de Chile, al Protector del Perú y al Director Supremo de Buenos Aires, Cali, 9 de enero de 1822. Bolívar, Cartas del Libertador, t. III, segunda edición, Banco de Venezuela y Fundación Vicente Lecuna, Caracas, 1965, págs. 181-184. Las instrucciones giradas a los plenipotenciarios colombianos se encuentran en: Pedro Gual a Joaquín Mosquera, Cúcuta, 11 de octubre de 1821 y Bogotá 28 de diciembre de 1821; Gual a Miguel Santamaría, Bogotá, 10 de octubre de 1821, Vicente Lecuna, Relaciones diplomáticas de Bolívar con Chile y Buenos Aires, t. I, Imprenta Nacional, Caracas, 1954, págs. 7-14 y 35-40.

${ }^{61}$ Tratado de unión, liga y confederación perpetua entre Colombia y el Perú, y Tratado para formar la Asamblea de plenipotenciarios, Lima, 6 de julio de 1822, Ídem, págs. 14-18 y 19-22.

${ }^{62}$ Tratado de unión, liga y confederación entre Colombia y Chile, Santiago, 21 de octubre de 1822 , Ídem, págs. 22-28.

63 Tratado de amistad, unión, liga y confederación entre Colombia y Méjico (sic), 3 de octubre de 1823, Ídem, págs. 29-34; Primera Secretaría de Estado, Sección de Estado. Texto publicado el 20 de septiembre de 1825 luego de las correspondientes ratificaciones. Acervo Histórico Diplomático Mexicano (AHDM), “Conferencias de Panamá y Tacubaya”, Legajo Encuadernado (L.E.) 869 I, años 1825-26, 9-11.

64 Tratado entre Centro América y Colombia (fragmentos), Bogotá, 15 de marzo de 1825, José Rodríguez Cerna, Centroamérica en el Congreso de Bolivar: Contribución documental, inédita, para la historia de la Primera Asamblea Americana, Tipografía Nacional, Guatemala, 1956, págs. 2526; Tratado de unión, liga y confederación entre Colombia y Centroamérica, 15 de marzo de 1825 , Enrique Gaviria Liévano, Politica exterior colombiana. Nuestro Archipiélago de San Andrés y el Tratado con Nicaragua, t. I, Universidad Externado de Colombia, Bogotá, 2001, págs. 333-337.

65 “Asamblea Hispanoamericana”, La Abeja Chilena, Santiago, 15 de julio de 1825, Colección de antiguos periódicos chilenos, Santiago, 1966, pp. 35. En el mismo número se inserta el Tratado de 
Araucana reproduce sin comentarios un extracto de la Gaceta del Gobierno de Lima que defiende a Bolívar de la acusación de querer dominar a las nuevas repúblicas ${ }^{66}$. En octubre, esa misma publicación reproduce y esta vez comenta favorablemente un artículo de Argos de Buenos Aires contrario al Congreso anfictiónico ${ }^{67}$. En un año, la opinión sobre el Congreso cambia de un inicial entusiasmo a una mediana oposición. Cuando el congreso chileno nombra como ministros plenipotenciarios a Joaquín Campino y José Miguel Infante en octubre de 1826, la iniciativa es extemporánea y estéril. La asamblea se ha mudado a México donde esperará infructuosamente la llegada de los tratados de Panamá con la debida ratificación.

A lo largo de este periodo, Egaña insiste en hacer avanzar el proyecto de la confederación. Actúa en solitario, más allá de los vaivenes del movimiento de la confederación y en cierta forma viene a encarnar la continuidad del ideal de la Patria Grande a lo largo del periodo independentista chileno ${ }^{68}$. En 1826 redacta un Acta de Confederación y bajo el probable influjo de la propuesta aliancista de Francisco de Paula Santander, vicepresidente de la Gran Colombia, decide incluir en la confederación a Estados Unidos, España, Portugal, Grecia y Haití ${ }^{6}$. En paralelo elabora unas bases que desea proponer a la asamblea del Istmo, "Instrucción en proyecto", aunque no llegan a conocerse fuera de Chile $^{70}$.

\section{Conclusiones}

Salvo en un caso, los escritos independentistas difundidos en Santiago de Chile entre 1810 y 1813 proponen, justifican y buscan llevar a cabo la reunión confederativa de las secciones de Hispanoamérica. Conciben al congreso general como un instrumento capaz de reforzar los lazos transversales y éstos como un componente necesario de la Emancipación. No solo buscan sumar esfuerzos para lograr la Independencia hispanoamericana: cuando se define, el congreso confederativo incluye la unificación de la defensa y la diplomacia externa, la garantía del respeto a la integridad de las nuevas repúblicas y la pacificación de las relaciones interiores mediante el arbitraje. Si bien no logran su cometido y

unión, liga y confederación perpetua de Colombia y Perú.

${ }_{66}$ "Extracto de la Gazeta de Lima del 16 de junio del presente año", La Década Araucana, Santiago, 20 de agosto de $1825, n^{\circ} 4$, idem, pp. 204-206.

67 "Extracto del Argos de Buenos Aires, números 189 y 190 del 21 y 24 de septiembre de 1825", $L a$ Década Araucana, Santiago, 28 de octubre de 1825, n 9, idem, pp. 264-271.

${ }^{68}$ El término Patria Grande no se emplea entonces. Es acuñado por Manuel Ugarte a principios del siglo XX. Cfr. La Patria grande, Editorial Internacional, Barcelona, 1922.

${ }^{69}$ Egaña, "Acta de Confederación y mutua garantía de la independencia de los Estados que en él se mencionan", Silva Castro, Escritos inéditos y dispersos, págs. 58-62.

${ }^{70}$ Egaña, Colección de algunos escritos politicos, morales, poéticos y filosóficos, t. VI, Imprenta Laplace y Beaume, Burdeos, 1836. 
su dirección es cada vez menos seguida, estos manifiestos constituyen las bases ideológicas que preparan y facilitan la acción combinada de los ejércitos de San Martín y O’Higgins en 1817, y más tarde la participación de Chile en el vasto ensayo confederativo de la década de 1820.

En conjunto, las variantes del ideal de congreso general apuntalan una tendencia no reconocida por la historiografía mayoritaria, que ve en el proceso independentista exclusivamente una protohistoria nacional, y en el proyecto de congreso un riesgo de supresión de las nuevas soberanías. El llamado ecuménico bosqueja una finalidad que no contradice la fundación republicana, por cuanto aspira a coexistir con el desenvolvimiento de las repúblicas. Aunque los escritos no emplean el término de Patria Grande, asumen sus implicaciones cuando programan el aprovechamiento de la identidad común en pro de una inserción internacional con mayor capacidad defensiva y ordenamiento interno.

\section{Periódicos}

Aurora de Chile (1812-1813)

El Monitor Araucano (1813)

La Abeja Chilena (1825)

La Década Araucana (1825)

\section{Referencias}

Amor de la Patria, José, Catecismo político Cristiano dispuesto para la instrucción de la Juventud de los Pueblos libres de la América Meridional, Colección de historiadores i de documentos relativos a la independencia de Chile, vol. XVIII, Imprenta Cervantes, Santiago, 1910, págs. 113-147.

Amunátegui, Miguel Luis, Camilo Henríquez, Imprenta Nacional, t. I, Santiago, 1889.

Amunátegui, Miguel Luis, Los precursores de la Independencia de Chile, t. III, Imprenta, Litografía y Encuadernación Barcelona, Santiago, 1910.

Amunátegui, Miguel Luis, Los primeros años del Instituto Nacional, 1813-1835, Imprenta Cervantes, Santiago, 1889.

Anónimo, "Reflexiones sobre la libertad Americana", El Monitor Araucano, n $^{\circ}$ 64, 65, 66 y 67, septiembre de 1823, Santiago. 
Archivo Nacional, Archivo del don Bernardo O'Higgins, t. I, Editorial Nascimento, Santiago, 1946.

Argomedo, José Gregorio, "Diario de los sucesos ocurridos en Santiago desde el 10 hasta el 22 de septiembre de 1810", La Revista Nueva, Año I, t. II, Santiago, 1900, págs. 137-168.

Baeza Ruz, Andrés, "Elightenment, education, and the republican Project: Chile's Instituto Nacional (1810-1830)", Paedagogica Historica, vol. 46, $\mathrm{n}^{\circ} 4$, 2010, págs. 479-493.

Barnadas, Joseph M., Diccionario histórico de Bolivia, Sucre, 2002.

Barros Arana, Diego et al., Colección de historiadores $i$ de documentos relativos a la independencia de Chile, vol. XIX, Santiago, 1925.

Barros Arana, Diego, Historia General de Chile, t. XII, Editorial Universitaria - Centro de Investigaciones Diego Barros Arana, segunda edición, Santiago, 2005.

Bello, Andrés, Obras Completas, Vol. X, Impreso por Pedro G. Ramírez, Santiago, 1886.

Bolívar, Simón, Cartas del Libertador, t. III, segunda edición, Banco de Venezuela y Fundación Vicente Lecuna, Caracas, 1965.

Campos Harriet, Fernando, "Don Juan Martínez de Rozas, jurista de los finales del periodo indiano", Actas y Estudios del VII Congreso del Instituto Internacional de Historia del Derecho Indiano, Buenos Aires, 1-6 de agosto, 1983, págs. 195-210.

Cavieres, Eduardo, "Lo deseado y lo ejecutado: ideas y acciones, temas y problemas sobre la Independencia nacional, las representaciones y la construcción de Estado", Espacio Regional, vol. 2, n 7, Osorno, 2010, págs. 25-37.

Cid Celis, Gustavo, Juan Egaña, constitucionalista y prócer americano, Imprenta El Esfuerzo, Santiago, 1941.

Collier, Simon, Ideas y politica de la independencia chilena, 1808-1833, Fondo de Cultura Económica, Santiago, 2012.

Cuevas Cancino, Francisco, El pacto de familia. Historia de un episodio de la diplomacia mexicana en pro de la anfictionía, Secretaría de Relaciones Exteriores, México, t. I, 1962.

Donoso, Ricardo, "El Catecismo Político-Cristiano", Revista Chilena de Historia y Geografía, n 102, 1943, págs. 12-119.

Egaña, Juan, Colección de algunos escritos políticos, morales, poéticos y filosóficos, t. VI, Imprenta Laplace y Beaume, Burdeos, 1836.

Egaña, Proyecto de una constitución para el Estado de Chile que por disposición del Alto Congreso escribió el senador D. D. Juan Egaña en el año 1811 y que hoy manda publicar el Supremo Gobierno, modificado según el dictamen que por orden del mismo Gobierno le precede El Proyecto de 
declaración de los derechos del pueblo de Chile, modificado según el dictamen que por orden del mismo Gobierno se pidió al autor, Imprenta del Gobierno por D. J. C. Gallardo, Santiago, 1813.

Egaña, Juan, Tractatus de re Logica, Metaphisica et Morali: Pro Filiis et Alumnis Instituti Nationalis Jacobo Politanae Erudiensis, Tipografía Raimundo Rengifo, Santiago, 1827.

Egaña, Juan, Memoria politica sobre si conviene en Chile la libertad de cultos. Reimpresa en Lima con una breve apología del art. 8 y 9 de la constitución política del Perú de 1823, Imprenta por La Libertad por J. M. Masias, Lima, 1827.

Hanish Espíndola, Walter, El Catecismo político cristiano. Las ideas y la época: 1810, Editorial Andrés Bello, Santiago, 1970.

García-Huidobro, Cristóbal, "El Reglamento Constitucional Provisorio de 1812: Reflexiones para un Bicentenario", Revista Chilena de Derecho, vol. 39, $\mathrm{n}^{\circ} 1$, Santiago, 2012, págs. 235-243.

Gaviria Liévano, Enrique, Politica exterior colombiana. Nuestro Archipiélago de San Andrés y el Tratado con Nicaragua, t. I, Universidad Externado de Colombia, Bogotá, 2001.

Gay, Claudio, Historia de la Independencia Chilena, t. II, Impr. de E. Thunot, París, 1856.

Gazmuri, Cristián, "Libros e ideas francesas en la gestación de la Independencia de Chile”, Caravelle, n 54, Toulouse, 1990, págs. 179-207.

Góngora, Mario de, "El pensamiento de don Juan Egaña sobre la reforma eclesiástica", Estudios de historia de las ideas e historial social, Universidad Católica de Valparaíso, Santiago, 1980.

Guerrero Lira, Cristian, "El proyecto constitucional de Joel R. Poinsett para Chile, 1812, Cuadernos de Historia, vol. 37, Santiago, 2012, págs. 225 240.

Just Lleó, Estanislao. Comienzo de la independencia en el Alto Perú: los sucesos de Chuquisaca, 1809, Editorial Judicial, Sucre, 1994.

Lecuna, Vicente, Relaciones diplomáticas de Bolivar con Chile y Buenos Aires, t. I, Imprenta Nacional, Caracas, 1954.

López, Francisco A., José M. Infante, Agustín Eyzaguirre y Jaime Zudáñez, Manifiesto del Gobierno de Chile a las naciones de América y Europa, Imprenta de Gobierno, P. D. J. C. Gallardo, Santiago, 1813.

Mercier, Louis-Sébastien, L'An deux mille quatre cent quarante, Rêve s'il en fut jamais, Londres, 1772.

Reza, Germán A. de la, Documentos sobre el Congreso anfictiónico de Panamá, Fundación Ayacucho, Caracas, 2010.

Reza, Germán A. de la, El ciclo confederativo. Historia de la integración latinoamericana en el siglo XIX, Universidad de San Marcos, Lima, 2012. 
Roca, José Luis, Ni con Lima ni con Buenos Aires. La formación de un Estado nacional en Charcas, Plural Editores, segunda edición, La Paz, 2011.

Rodríguez Cerna, José, Centroamérica en el Congreso de Bolivar: Contribución documental, inédita, para la historia de la Primera Asamblea Americana, Tipografía Nacional, Guatemala, 1956.

Silva Castro, Raúl, “Juan Egaña, Precursor de la Integración Americana”, Estudios Internacionales, vol. 2, $\mathrm{n}^{\circ} 3$, Instituto de Estudios Internacionales de la Universidad de Chile, Santiago, 1968, pág. 387.

Silva Castro, Raúl, Escritos políticos de Camilo Henríquez, Universidad de Chile, Santiago, 1960.

Silva Castro, Raúl, Juan Egaña. Escritos inéditos y dispersos, Imprenta Universitaria, Santiago, 1949.

Silva Castro, Raúl, Los primeros años de la Biblioteca Nacional (18131824), Imprenta Universitaria, Santiago, 1951.

Tocornal y Grez, Manuel Antonio, Memoria sobre el primer gobierno nacional, leída en la sesión pública de la Universidad de Chile el 7 de noviembre de 1847, Universidad de Chile, Santiago, 1866. 1922.

Ugarte, Manuel, La Patria grande, Editorial Internacional, Barcelona,

Ulloa, Alberto, Congresos americanos de Lima, t. I, Archivo Diplomático del Perú, Imprenta Torres Aguirre, Lima, 1938.

Voltaire, De la paix perpétuelle par le docteur Goodhearth, M.M. Rey, Amsterdam, 1769. 